\title{
Variation in morphometric and meristic traits of Aspidoparia morar from Brahmaputra and Barak Rivers of Assam, India
}

\author{
Simanku Borah*, Asha T. Landge, Birendra K. Bhattacharjya ${ }^{1}$, Sushant K. Chakraborty, \\ Karankumar K. Ramteke, Jyotish Barman, Kaustubh Bhagawati and Bhaskar J. Saud ${ }^{\mathbf{1}}$
}

Central Institute of Fisheries Education, Indian Council of Agricultural Research, Panch Marg, Off Yari Road, Versova, Andheri West, Mumbai- 400061, INDIA

${ }^{1}$ Central Inland Fisheries Research Institute, Indian Council of Agricultural Research, Guwahati Regional Centre, Housefed Complex, Dispur, Guwahati- 781006 (Assam), INDIA

*Corresponding author. E-mail: simankuborah@gmail.com

Received: April 26, 2014; Revised received: May 15, 2014; Accepted: June 3, 2014

Abstract: The minor carp, Aspidoparia morar is a benthopelagic fish belonging to the sub-family Danioninae under the family Cyprinidae. It has emerged as the single most dominant species in the river Brahmaputra in Assam. In the present study, 240 specimens were collected from Guwahati and Tezpur in the Brahmaputra River and Silchar in the Barak River to investigate the morphometric and meristic variation among the populations. For this a total of 20 morphometric traits and 11 meristic traits were studied. The mean lengths for most of the morphometric traits were higher for the Barak River except eye diameter, inter orbital length and anal fin length which were significantly higher on the Brahmaputra River, while the post orbital length and pelvic fin length were found to be almost equal. The regressions of standard length with all the morphometric traits except pelvic fin length, pelvic fin base, pectoral fin length, dorsal fin length, anal fin length, pre orbital length, post orbital length, inter orbital length and eye diameter showed significant variation between the rivers. Two meristic traits viz. branched rays in anal fin and gill rakers on the first gill arch also showed significant variation in the samples of the rivers.

Keywords: Aspidoparia morar, Brahmaputra, Barak, Meristic, Morphometric

\section{INTRODUCTION}

The analysis of morphometric and meristic characters is one of the most commonly used methods in stock identification. Changes in morphometric characteristics are typically seen to change over a number of generations, slowly and gradually because of selective environmental pressures. Morphometric variability among different geographical populations would be attributed either to distinct genetic structure or to environmental conditions in each area (Kinsey et al., 1994). Morphometric analysis provides information on phenotypic stocks, groups of individuals with similar growth, mortality and reproductive rates (Booke, 1981). Meristic counts may differ as a result of environmental differences during early development (Colman, 1976). Phenotypic variation, such as meristic counts, continues to play an important role in stock identification among groups of fish, despite use of genetic analysis (Swain and Foote, 1999).

Aspidoparia morar (Hamilton, 1822), a small sized minor carp, is one of the most dominant species in Brahmaputra and Barak rivers in Assam, India. The species belongs to the sub-family Danioninae under the family Cyprinidae. CIFRI, Barrackpore has been estimating the fish yield and catch composition in different landing centers of River Brahmaputra in Assam, especially that of Uzanbazar landing centre since 1973. These studies have shown that the miscellaneous finfish species have started dominating the total catch (40-50\%) and a minor carp, A. morar has emerged as the most dominant fish species at all major landing centers (Vaas et al., 2011). The present study deals with the variation in morphometric and meristic traits of A. morar from the two rivers of Assam.

\section{MATERIALS AND METHODS}

A total of 240 fish samples were collected from Barak River (Silchar) and from Brahmaputra River (Guwahati and Tezpur) between $15^{\text {th }}$ October 2012 to $16^{\text {th }}$ March 2013. Aspidoparia morar was identified as per the description given in Inland Fishes of India and Adjacent Countries (Talwar and Jhingran, 1991). Samples, without any physical damages were collected randomly from the selected fish landing centers. The collected fish specimens were placed in insulated box with ice packs. The cover was sealed with an insulated tape and was transported to the laboratory. Fishes, with normal morphological features were used for the present study. No other organisms were harmed during 
the present study. A total of 20 morphometric traits were measured using digital Vernier caliper. 11 meristic traits were also counted for analysis (Table 1). The data was analysed with the help of SAS software.

\section{RESULTS}

The mean lengths for most of the morphometric traits were higher for the Barak River except eye diameter, inter orbital length and anal fin length which were significantly higher on the Brahmaputra River, while the post orbital length and pelvic fin length were found to be almost equal (Table 2). A significant difference was seen between the rivers in all the morphometric traits. With regard to the correlation between various morphometric traits was found to be positive, high and significant. The correlation coefficient of total length with head length, pre dorsal length, dorsal fin length, pre anal length, maximum body depth were obtained as $0.93,0.97,0.70,0.96$ and 0.92 , respectively. The correlation of maximum body depth with head length and head length with pre dorsal length were estimated as 0.87 and 0.91 , respectively. The correlation of dorsal fin length with pre dorsal fin length was 0.67 and dorsal fin length with dorsal fin base length was found to be 0.60 . Eye diameter also showed a higher correlation (0.82) with the head length. The correlation of anal fin length (0.24) with pre anal length and the anal fin length (0.31) with the total length was on the lower side. Similarly, inter orbital length and pre orbital length shows a slightly lower correlation of 0.51 . The mean sum of squares and model $R^{2}$ values from the analysis of variance for morphometric traits are given in table 3 . The regressions of all the traits on standard length are significant. The model $\mathrm{R}^{2}$ values ranged from 5.30 to $58.69 \%$. The regressions of standard length with all the morphometric traits except pelvic fin length, pelvic fin base, pectoral fin length, dorsal fin length, anal fin length, pre orbital length, post orbital length, inter orbital length and eye diameter showed significant variation between the rivers.

Out of 11 meristic traits studied, 2 were considered for the analysis of variability as others were constant in their value. The overall counts of branched rays in anal fin and gill rakers on the first gill arch (Table 4) ranged from 9-10 and 20-22 respectively. The anal fin unbranched rays counts of the Barak and Brahmaputra River were 9 and 10 respectively while the gill rakers count varied from 20-21 and 20-22 respectively.

\section{DISCUSSION}

During the present study it has been observed that the average length of fishes collected from the Barak River was significantly higher than that from the Brahmaputra River. Significant differences were observed in total length, standard length, fork length, pre anal length, pre dorsal length, maximum body depth and caudal peduncle depth. This variation may be the result of high rate of sedimentation and heavy pollution load due to the presence of a number of industries, followed by high turbidity in the Brahmaputra River resulting in low food availability in the form of plankton required for the growth of individuals. Moreover the reduced mean length of the species from the River Brahmaputra can be attributed to the high fishing pressure encountered by the species in the river.

For planktivorous fish, feeding ability was reduced under turbid conditions (Gardner, 1981) while turbidity reduced growth rates in juvenile salmonids (Sigler et al., 1984). Turbidity decreases visibility in aquatic systems by decreasing light penetration and also reduces the plankton density of the system. This affects the food availability and feeding rate of the planktivorous fishes leading to low fish productivity. Swain et al. (2007) stated that drop in mean length is the consequence of exploitation pressure by size.

Table 1. Morphometric and meristic traits of $A$. morar.

\begin{tabular}{|c|c|c|c|}
\hline S. N. & Morphometric traits & S. N. & Meristic traits \\
\hline 1 & Total length & \multirow{2}{*}{1} & \multirow{2}{*}{ Unbranched fin rays on dorsal fin } \\
\hline 2 & Standard length & & \\
\hline 3 & Fork length & \multirow{2}{*}{2} & \multirow{2}{*}{ Branched fin rays on dorsal fin } \\
\hline 4 & Head length & & \\
\hline 5 & Pre orbital length & \multirow{2}{*}{3} & \multirow{2}{*}{ Unbranched fin rays on pectoral fin } \\
\hline 6 & Eye diameter & & \\
\hline 7 & Post orbital length & \multirow{2}{*}{4} & \multirow{2}{*}{ Branched fin rays on pectoral fin } \\
\hline 8 & Dorsal fin length & & \\
\hline 9 & Pectoral fin length & \multirow{2}{*}{5} & \multirow{2}{*}{ Unbranched fin rays on anal fin } \\
\hline 10 & Pectoral fin base length & & \\
\hline 11 & Dorsal fin base length & \multirow{2}{*}{6} & \multirow{2}{*}{ Branched fin rays on anal fin } \\
\hline 12 & Pelvic fin length & & \\
\hline 13 & Pelvic fin base length & \multirow{2}{*}{7} & \multirow{2}{*}{ Unbranched fin rays on pelvic fin } \\
\hline 14 & Pre Anal length & & \\
\hline 15 & Anal fin base length & \multirow{2}{*}{8} & \multirow{2}{*}{ Branched fin rays on pelvic fin } \\
\hline 16 & Anal fin length & & \\
\hline 17 & Caudal peduncle depth & \multirow{2}{*}{9} & \multirow{2}{*}{ Gill rakers on left side of the body } \\
\hline 18 & Maximum body depth & & \\
\hline 19 & Inter orbital length & 10 & Unbranched fin rays on caudal fin \\
\hline 20 & Pre Dorsal length & 11 & Branched fin rays on caudal fin \\
\hline
\end{tabular}


Simanku Borah et al. / J. Appl. \& Nat. Sci. 6 (1): 262-266 (2014)

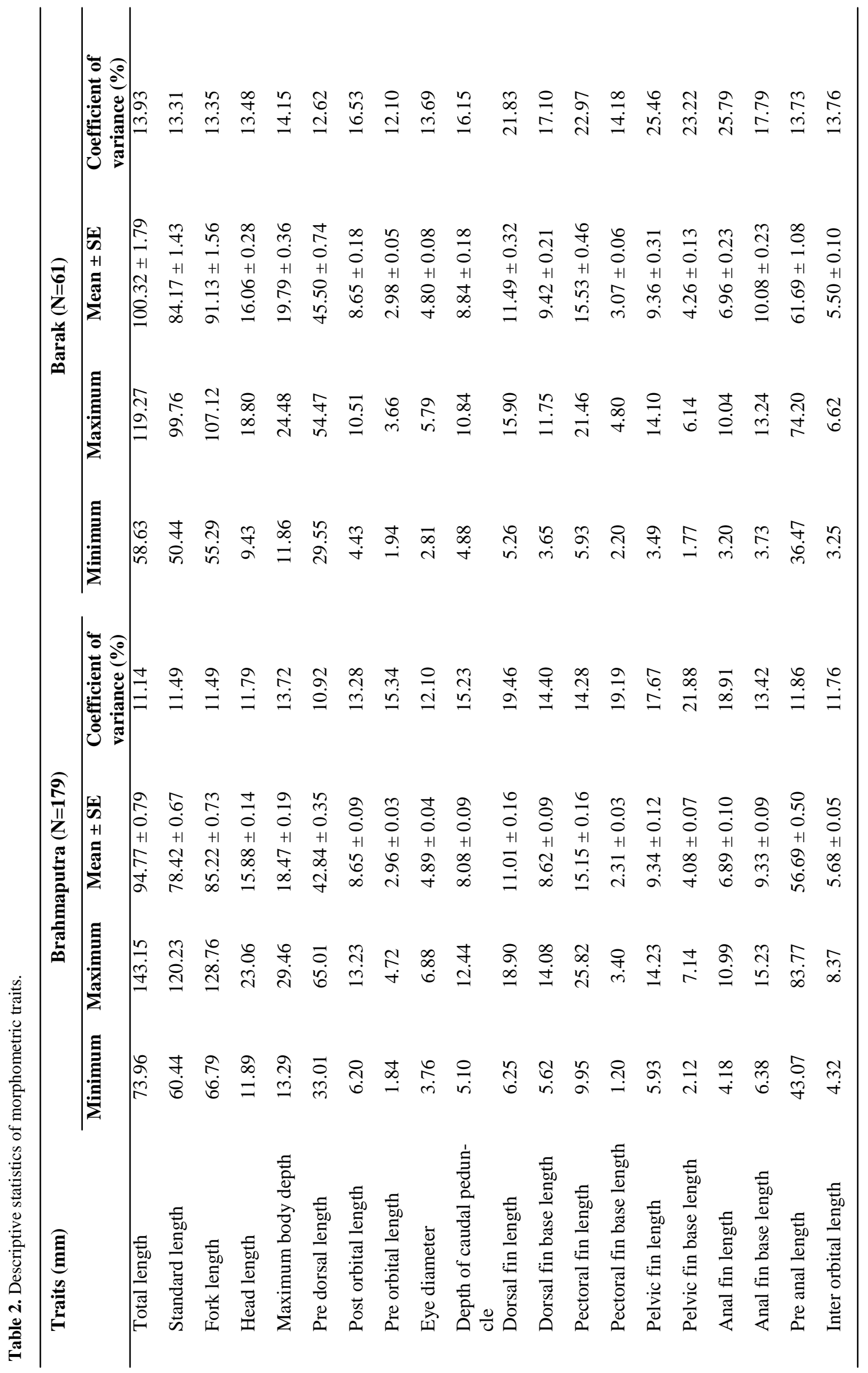


Table 3. Analysis of variance for different morphometric traits from the two rivers.

\begin{tabular}{lccc}
\hline Morphometric traits $(\mathbf{m m})$ & Degrees of freedom & Mean sum of squares & Model R$^{2}$ Value \\
\hline Total length & 1 & $1405.39^{* *}$ & 24.09 \\
Standard length & 1 & $1508.46^{* *}$ & 26.65 \\
Fork length & 1 & $1592.83^{* *}$ & 28.67 \\
Head length & 1 & $254.51^{* *}$ & 20.22 \\
Pre orbital length & 1 & $0.87 \mathrm{NS}$ & 8.29 \\
Eye diameter & 1 & $0.11 \mathrm{NS}$ & 30.32 \\
Post orbital length & 1 & $0.15 \mathrm{NS}$ & 22.82 \\
Dorsal fin length & 1 & $2.65 \mathrm{NS}$ & 21.43 \\
Pectoral fin length & 1 & $2.79 \mathrm{NS}$ & 17.42 \\
Pectoral fin base length & 1 & $26.85^{* *}$ & 58.69 \\
Dorsal fin base length & 1 & $29.45^{* *}$ & 20.62 \\
Pelvic fin length & 1 & $1.75 \mathrm{NS}$ & 5.42 \\
Pelvic fin base length & 1 & $0.09 \mathrm{NS}$ & 7.17 \\
Pre Anal length & 1 & $1139.05^{* *}$ & 31.06 \\
Anal fin base length & 1 & $25.76^{* *}$ & 12.86 \\
Anal fin length & 1 & $0.74 \mathrm{NS}$ & 5.30 \\
Caudal peduncle depth & 1 & $26.64^{* *}$ & 27.26 \\
Maximum body depth & 1 & $78.93^{* *}$ & 31.06 \\
Inter orbital length & 1 & $0.31 \mathrm{NS}$ & 27.13 \\
Pre Dorsal Length & 1 & $322.18^{* *}$ & 25.07 \\
\hline
\end{tabular}

$(* * \mathrm{P} \leq 0.01) ; \mathrm{NS}=$ Non Significant

Table 4. River wise frequency distribution of meristic characters of Aspidoparia morar.

\begin{tabular}{lccccccc}
\hline River & & \multicolumn{2}{c}{ Anal fin branched } & & Gill raker & \multicolumn{2}{c}{ Total } \\
\cline { 3 - 7 } & & $\mathbf{9}$ & $\mathbf{1 0}$ & $\mathbf{2 0}$ & $\mathbf{2 1}$ & $\mathbf{2 2}$ & \\
\hline Brahmaputra & Frequency & 0 & 179 & 10 & 151 & 18 & 179 \\
& Percent & 0.00 & 74.58 & 4.16 & 62.92 & 7.50 & 74.58 \\
Barak & Frequency & 61 & 0 & 54 & 7 & 0 & 61 \\
& Percent & 25.42 & 0.00 & 22.50 & 2.92 & 0.00 & 25.42 \\
Total & Frequency & 61 & 179 & 64 & 158 & 18 & 240 \\
& Percent & 25.42 & 74.58 & 26.67 & 65.83 & 7.50 & 100.00 \\
\hline
\end{tabular}

It has been observed that the maximum caudal peduncle depth of fishes from Barak River is significantly higher than the Brahmaputra. Relationship between deeper caudal peduncle depth and turbulent water has been reported by Imre et al. (2002). He demonstrated the morphological variation in caudal region of brook charr (Salvelinus fontinalis) from microhabitats differing in water velocity and has observed deeper caudal peduncle in fishes from turbulent waters. The Barak River is narrow and steep, as compared to the Brahmaputra, which is very wide. The Barak valley is a part of the Meghalaya plateau and is characterized by hilly terrain, while the Brahmaputra valley is completely a plain area. Therefore the water velocity in the Barak is higher compared to the mighty Brahmaputra. Thus it appears that the relatively greater depth of caudal peduncle of A. morar from the Barak River, may be due to the turbulent water in which it inhabits.

Among all vertebrates fishes exhibit greater variance in morphological traits and are more susceptible to environmentally induced morphological variation (Dunham et al., 1979). Thus environmental variations in the form of temperature, food availability, water current, water quality and other features may determine the phenotypic variation in A. morar. Phenotypic variation also indicates that majority of the fishes spend their entire lives in geographically isolated regions. Meristics characters are generally set early in ontogeny and remain stable throughout life, thus reflecting environmental effects over a relatively brief time of larval development. As a result, significant statistical differences may occur within a stock among year classes or geographic subgroups subjected to varying environmental conditions. However consistent environmental influences can probably provide discrimination in stocks provided there is genetic divergence between the actual stocks (Hubbs and Laglar, 1958; Begg and Waldman, 1999). Values attained for meristic features are usually the results of interactions between genetics and environment (Marr, 1957; Swain and Foote, 1999).

Variation in the gill raker counts has been noticed in the samples from the two rivers. Moodie (2004) reported that variation in gill raker numbers within species significantly vary in tropical species. Amundsen et al. (2004) reported that variation in gill rakers is related to the difference in inter-raker spacing. Variation in inter-raker spacing in fishes is related to the prey size (Matsumoto and Kohda, 2001). 
Lindsey (1981) reported that physiological parameters as water temperature also affects gill raker morphology, which seems related to the present study.

\section{Conclusion}

Fish stocks identification is very much essential for effective fisheries management. Stock identification also forms the basis for fish Stock assessment. Traditional tools such as morphometric and meristic characters are of significant importance in identifying fish stocks. Studies at molecular level can be made in the future to validate the present findings.

\section{REFERENCES}

Amundsen, P. A., Born, T. and Vaga, G. H. (2004). Gill raker morphology and feeding ecology of two sympatric morphs of European white fish (Coregonus lavaretus). Annales Zoologici Fennici, 41: 291-300.

Begg, G. A. and Waldman, J. R. (1999). A holistic approach to fish stock identification. Fisheries Research, 43: 3544.

Booke, H. E. (1981). The conundrum of the stock conceptare nature and nurture definable in fishery science? Canadian Journal of Fisheries and Aquatic Sciences, 38: $1479-1480$.

Colman, J. (1976). Geographical variation in fin ray numbers in the New Zealand sand flounder (Rhombosolea plebian). New Zealand Journal of Marine and Freshwater Research, 10(3): 485-97.

Dunham, A. E., Smith, G. R. And Taylor, J. N. (1979). Evidence for ecological character displacement in western American catostomic fishes. Evolution, 33:877896.

Gardner, M. B. (1981). Effects of turbidity on feeding rates and selectivity in bluegills. Transactions of the American Fisheries Society, 110: 146-450.

Hamilton, F. (1822). An account of the fishes found in the river Ganges and its branches. Archibald Constable and Company, Edinburgh, pp. 264.

Hubbs, C. L. and Laglar, K. F. (1958). Fishes of the great lakes region. Ann Arbor. University of Michigan Press, pp. 213.

Imre, I., McLaughlin, R. L. and Noakes, D. L. G. (2002).
Phenotypic plasticity in brook charr: changes in caudal fin induced by water flow. Journal of Fish Biology, 61:1171-1181.

Kinsey, S. T., Orsoy, T., Bert, T. M. and Mahmoudi, B. (1994). Population structure of the Spanish sardine Sardinella aurita : Natural morphological variation in a genetically homogenous population. Marine Biology, 118: 309.

Lindsey, C. C. (1981). Stocks are chameleons: plasticity in gill rakers of coregonid fishes. Canadian Journal of Fisheries and Aquatic Sciences, 38: 1497-1506.

Marr, J. C. (1957). The subpopulation problem in the Pacific sardine, Sardinops caurulea. United States Fisheries and Wildlife Service Special Scientijc Report on Fisheries, 208: 25-108.

Matsumoto, K. and Kohda, M. (2001). Differences in gill raker morphology between two local populations of a benthophagous filter-feeding fish, Goniistius zonatus (Cheilodactylidae). Ichthyological Research, 48:269273.

Moodie, G. E. (2004). Gill raker variation and the feeding niche of some temperate and tropical freshwater fishes. Environmental Biology of Fishes, 13 (1): 71-76.

Sigler, J. W., Bjornn, T. C. and Everest, F. H. (1984). Effects of chronic turbidity on density and growth of steelheads and coho salmon. Transactions of the American Fisheries Society, 113:142-150.

Swain, D. and Foote, C. (1999). Stocks and chameleons: the use of phenotypic variation in stock identification. Fisheries Research, 43:113-28.

Swain, D. P., Sinclair, A. F. and Hanson, M. J. (2007). Evolutionary response to size- selective mortality in an exploited fish population. Proceedings of the Royal Society B, 274: 1015-1022.

Talwar, P.K. and Jhingran, A.G. (1991). Inland fishes of India and adjacent Countries. Oxford and IBH Publishing Co. Pvt. Ltd., New Delhi-Calcutta. Vol. I, pp. 340.

Vaas, K. K., Das, M. K., Tyagi, R. K., Katiha, P. K., Samanta, S., Shrivastava, N. P., Bhattacharjya, B. K., Suresh, V. R., Pathak, V., Chandra, G., Debnath, D. and Gopal, B. (2011). Strategies for sustainable fisheries in the Indian part of the Ganga-Brahmaputra River Basins. International Journal of Ecology and Environmental Sciences, 37(4): 157-218. 